Pesquisa e Reflexão em Educação Básica

\title{
Os jovens entre a escola e o trabalho: tensões e contradições
}

Iza Reis Gomes Ortiz ${ }^{1}$

Luiz Antonio da Fontoura Colussi ${ }^{2}$

\begin{abstract}
Resumo:
O presente artigo discute as relações estabelecidas entre jovens do Ensino Médio, o mundo do trabalho e projetos de vida. Seu objetivo foi compreender as implicações e influências das atuais formas de trabalho para o projeto de vida destes estudantes, utilizando como categorias analíticas as bases conceituais de acumulação flexível e compressão espaço-tempo, de David Harvey (1993). Este trabalho foi realizado por meio de uma pesquisa bibliográfica buscando apreender a complexidade dos desafios da inserção laboral que se apresentam atualmente aos jovens, em consequência das últimas transformações e precarizações que o neoliberalismo vem impondo ao mundo do trabalho. o principal resultado que a pesquisa indicou é que persistem grandes dificuldades das instituições de Ensino Médio compreenderem as demandas, anseios e expectativas juvenis sobre seus projetos de vida, incluindo tais saberes e práticas em seus conteúdos curriculares e extracurriculares, visando a ressignificação da escola como instituição de socialização, emancipação e cidadania, rompendo com sua dimensão minimalista e mercadológica como formação intelectual de forma fragmentada e de adestramento ao mercado de trabalho.
\end{abstract}

\section{Palavras-chave:}

Ensino Médio. Educação Profissional e Tecnológica. Juventude. Mundo do Trabalho.

\section{Youth torn between school and work: tensions and contradictions}

\begin{abstract}
This article examines the relationships established between high school students, the job market and life aspirations. The purpose of this work was to understand the implications and influences of current forms of work for the life aspirations of these students, using David Harvey's (1993) concepts of flexible accumulation and space-time compression as analytical categories. This work was carried out by researching bibliography seeking to understand the complexity of the challenges of job insertion that young people have to face as a result of the latest transformations and
\end{abstract}

\footnotetext{
1 Doutora em Sociedade e Cultura na Amazônia, Professora de Língua Portuguesa e Literatura do IFRO. E-mail: iza.reis@ifro.edu.br. ORCID iD: https://orcid.org/0000-0001-8668-1692.

2 Mestrando em Educação Profissional e Tecnológica no ProfEPT. E-mail: luizcolussi2020@gmail.com. ORCID iD: http://orcid.org/0000-0002-3227-3498.
} 
precarization that neoliberalism has imposed on jobs. The research mainly pointed out that there is still major difficulty for high school institutions to understand the demands, desires and expectations of young people regarding their aspirations in life, including content and practices in their curricular and extracurricular activities aiming at redefining the school as an institution that fosters socialization, emancipation and citizenship - distancing itself from its minimalist and marketing dimension of fragmented intellectual teachings and domestication for the job market.

Keywords: High School. Professional and Technological Education. Youth. World of Work.

\section{Los jóvenes entre la escuela y el trabajo: tensiones y contradicciones}

Resumen: El presente artículo discute las relaciones establecidas entre jóvenes de lo Enseñanza Media, el mundo del trabajo y proyectos de vida. Su objetivo fue comprender las implicaciones e influencias de las actuales formas de trabajo para el proyecto de vida de estos estudiantes, utilizando como categorías analíticas las bases conceptuales de acumulación flexible y compresión espacio-tiempo, de David Harvey (1993). Este trabajo fue realizado por medio de una búsqueda bibliográfica buscando aprender la complejidad de los desafíos de la inserción laboral que se presentan actualmente a los jóvenes, en consecuencia de las últimas transformaciones y precarizaciones que el neoliberalismo viene imponiendo al mundo del trabajo. El principal resultado que la búsqueda indicó es que persisten grandes dificultades de las instituciones de enseñanza media en comprender las demandas, deseos y expectativas juveniles sobre sus proyectos de vida, incluyendo tales saberes y prácticas en sus contenidos curriculares y extracurriculares, objetivando la resignificación de la escuela como institución de socialización, emancipación y ciudadanía, rompiendo con su dimensión minimalista y mercadológica como formación intelectual de forma fragmentada y de adiestramiento al mercado de trabajo.

Palabras clave: Enseñanza Media. Educación Profesional y Tecnológica. Juventud. Mundo del Trabajo.

\section{Introdução}

O estudo aqui proposto compreende uma revisão bibliográfica dos impactos que algumas transformações econômicas, trabalhistas e sociais dos principais países capitalistas do mundo tiveram sobre as políticas públicas brasileiras, com relação ao trabalho e à educação para os jovens do Ensino Médio.

A metodologia aqui realizada se constitui em investigação sobre os condicionantes do mercado de trabalho brasileiro para os projetos de vida dos jovens da educação profissional e tecnológica, utilizando-se como ferramentas as categorias analíticas propostas por Harvey (1993) de "compressão espaço-tempo" e de "acumulação flexível", como estratégia a fim de compreender as perspectivas laborais juvenis na modernidade.

Vivenciamos atualmente um cenário de profundas desigualdades no campo social, onde os avanços científicos e tecnológicos que aumentam os lucros do capital e trazem benefícios a uma minoria da população, agravam a precarização da "classe-que-vive-do trabalho" (ANTUNES, 2009), a partir de sua superexploração mediante a crise de desemprego estrutural.

Segundo dados do Programa Nacional de Amostra por Domicílio do Instituto Brasileiro de Geografia e Estatística (2019), até o último trimestre daquele ano, o Brasil possuía 3,997 milhões de jovens entre 18 e 24 anos desempregados, representando 25,7\% do total da população brasileira nesta faixa etária. Um universo de 7,337 milhões de jovens subutilizados ou que tinham possibilidade de trabalhar mais horas na semana. 
Outra pesquisa da Organização Internacional do Trabalho (SILVA, 2015) que traz o título Juventude e Trabalho Informal no Brasil traz importantes análises relacionando que fatores como gênero, cor, raça, etnia, possuir ou não filhos etc., possuem significativa influência no desemprego: constatou-se que os brancos têm menor possibilidade de permanecerem desempregados, sugerindo que mulheres e jovens, assim como não-brancos (pretos e pardos) sofrem discriminação no mercado de trabalho nacional. Segundo este mesmo documento, as principais características da inserção ocupacional da juventude (com idade entre 18 e 24 anos) podem ser sintetizadas em 6 aspectos: desemprego 2 a 3 vezes superior às demais categorias etárias; alta rotatividade no emprego - sete em cada dez jovens desligam-se de seus postos de trabalho no decorrer de um ano; elevada taxa de informalidade, agravada em decorrência de raça, cor, etc.; jornada de trabalho semanal superior a 44 horas, o que gera enormes dificuldades para aqueles jovens que necessitam conciliar trabalho e estudo; desigualdade de gênero: mulheres com sobreposição de trabalhos reprodutivos às suas ocupações no mercado de trabalho; e baixa remuneração.

Os dados acima atestam que existem grandes precariedades e desigualdades radicalizadas no mundo do trabalho para os jovens, o que justifica a relevância da problematização aqui empreendida. Neste sentido, a Educação Profissional e Tecnológica (EPT), alicerçada na concepção educacional pela qual lutam as instituições vinculadas à Rede Federal de Educação Profissional, Científica e Tecnológica ${ }^{1}$, a qual busca formar integralmente o jovem em todas suas dimensões (cognitiva, cultural, tecnológica, histórica, científica, etc.), rompendo com o paradigma e preconceito histórico, estrutural e dualizante de nossa educação (educação propedêutica para as elites e profissionalizante para as classes trabalhadoras mais pobres), representa uma importante oportunidade aos jovens que, se do ponto de vista mercadológico, representa uma subordinação aos interesses do capital, do ponto de vista da sobrevivência representa ainda uma possibilidade de inserção social, sendo uma necessidade vital para muitos jovens das camadas populares mais precarizadas.

O artigo aqui desenvolvido se propõe a realizar uma reflexão sobre algumas implicações, determinações e repercussões sociais, econômicas e ideológicas que interferem nos projetos de vida dos jovens do Ensino Médio, utilizando como categoria analítica central o mundo do trabalho. $\mathrm{O}$ texto está dividido em três partes, a primeira versando sobre a centralidade do mundo do trabalho para o ser humano, a segunda tratando da concepção e importância dos projetos de vida para os jovens e a terceira buscando articular e refletir sobre as implicações resultantes da imbricação das categorias juventude, mundo do trabalho e projetos juvenis para os jovens-alunos do Ensino Médio. Por fim, são tecidas reflexões sobre as ideias discutidas no texto e apontadas as lacunas e possibilidades de aprofundamento investigativo sobre a temática.

\section{Dimensão e centralidade do trabalho para o ser humano}

Parte-se aqui do pressuposto de que não existe uma concepção única de trabalho aceita pela sociedade, pois cada sentido visa atender a interesses econômicos, ideológicos e políticos de um grupo de pessoas, servindo como instrumento de justificação das relações de poder. Frigotto (2009, p. 190) endossa essa visão ao afirmar

[...] que a polissemia do trabalho resulta de um complexo processo histórico nas relações sociais e vincula a produção material e cultural, mediante valores, símbolos, tradições, costumes. O sentido que vai assumir o trabalho tanto no senso comum como no âmbito das ciências, na sociedade de classes, resulta de relações de poder e dominação.

1 Instituída através da Lei n. 11.892, de 29 de dezembro de 2008 (BRASIL, 2008). 
Defende-se aqui a concepção de trabalho originada em Marx e Engels (2007) que assume o trabalho como categoria fundamental para o ser humano, compreendendo-o como um processo histórico em que o Homem, ao agir sobre a Natureza a fim de satisfazer suas necessidades transforma-a; e transformando-a, modifica a si mesmo, numa relação dialética. Diferentemente de todas as concepções anteriores, principalmente em confronto com a filosofia hegeliana que percebia a natureza humana enquanto uma idealização e abstração contemplativa, o Homem passa a ser entendido profundamente através do seu trabalho, do seu agir sobre o meio, construindo a partir daí sua essência e particularidade que o distingue dos outros animais. É a partir do agir teleológico $^{2}$ que o Homem transforma a Natureza e a si mesmo. Daí o trabalho possuir caráter ontológico (SAVIANI, 2007).

Ao mesmo tempo em que o trabalho responde pela produção de elementos imperativos à vida biológica dos seres humanos ele também é fator fundamental de todas as dimensões humanas: cultural, social, simbólica, afetiva, etc. (FRIGOTTO, 2010).

Entretanto, na sociedade moderna, o trabalho sob a condição histórica do modo capitalista de produção, na forma assalariada, assume uma perspectiva negativa que coisifica, aliena e fetichiza o trabalhador, desumanizando-o, ao reduzi-lo à condição de mercadoria, materializado através da compra e venda de sua força e capacidade de trabalho (MANACORDA, 2007).

Os adeptos ao neoliberalismo ${ }^{3}$ defendem uma lógica social que não mais estaria centrada no trabalho, mas sim nos novos paradigmas da sociedade da informação, sociedade do conhecimento e que a sociedade de classes e seus conflitos indissociáveis estaria superada pelo capitalismo (ANTUNES, 2009).

É fundamental e justificado, portanto, o embate ideológico pela concepção de Ensino Médio Integrado (EMI) à Educação Profissional e Tecnológica (EPT), da forma almejada pelos Institutos Federais de Educação, Ciência e Tecnologia, criada pela Lei no 11.892/2008, (BRASIL, 2008) como importante instituto social e transformador da área educacional, no sentido em que visa resgatar o sentido indissociável e central que o trabalho possui para o ser humano emancipar-se.

\section{A juventude e seus projetos de vida}

Na maioria das concepções da academia, segundo Dayrell, Leão e Reis (2011, p. 1068), “o jovem do ensino médio é compreendido apenas em sua condição de aluno, na dimensão cognitiva, ignorando sua construção social e histórica. Sua fase de vida, sua origem social, gênero e outros fatores são desprezados sob esta óptica".

Considerar o jovem que compõe o aluno implica em reconhecê-lo como indivíduo capaz de refletir e de se ver como participante da sociedade. Neste sentido, a oferta de tempos, espaços e relações de qualidade são condições fundamentais a fim de que estes possam experimentar e desenvolver suas potencialidades.

Além disso, necessitam de reflexões mais elaboradas acerca de seus desejos, habilidades, possibilidades e do contexto social onde se inserem, conhecendo a realidade do mundo do trabalho como elemento de forte relevância para a construção de seus projetos de vida.

\footnotetext{
2 Segundo Lukács (2013) consiste em uma ação humano-social mediatizada pela relação homem-natureza, com o objetivo de produzir valores de uso. É um processo de humanização do homem em que este, através da consciência, atribui finalidade a seu trabalho. 3 A concepção de neoliberalismo aqui adotada é a mesma de Gentilli (1995), que o caracteriza como um projeto de sociedade da classe burguesa que visa legitimar sua dominação através de um discurso ideológico nos campos político, econômico, jurídico e cultural. Trata-se de um vasto cânone apologético economicista que traz denominação nova - neo - para a antiga e repetitiva política do liberalismo, baseada na desregulamentação do capital, na privatização e no Estado mínimo, os quais colocam os interesses privados e do capital acima das necessidades materiais, sociais e humanas da coletividade.
} 
Cabe, portanto, problematizar como a escola de nível médio, em especial aquelas que executam a educação profissional e tecnológica, seus professores e gestores buscam conhecer e compreender as implicações entre juventude, mundo do trabalho e projetos de vida, sob a perspectiva de seus próprios jovens-alunos.

Inicialmente, se faz necessário explicitar o entendimento de projeto de vida aqui proposto. Tal concepção, originada em Schütz (1979), conforme citado por Dayrell, Leão e Reis (2011, p. 1071), pode ser compreendida pela ação do indivíduo escolher um rumo entre diferentes futuros possíveis, transformando suas fantasias e desejos em objetivos possíveis de serem realizados. Não se trata, portanto, de uma fórmula exata ou de uma estratégia definida, de um processo linear, tal como o percebe o senso comum.

Assim, os projetos de vida possuem dinâmica própria, estando em permanente estado de mutação, em conformidade com o amadurecimento dos jovens e com a amplitude de seu campo de possibilidades, ficando amplamente constrangidos (ou favorecidos) pelo contexto socioeconômico e cultural em que o jovem está inserido e que regula suas experiências.

\section{A dimensão do mundo do trabalho para os projetos de vida juvenis}

A partir do período pós-guerras, nos chamados 30 anos gloriosos (1945-1975), em que o Welfare State 4 e o ideal socialista possuíam grande legitimação social, sob a racionalidade fordista/ taylorista, o sistema de empregos possuía as garantias de formalidade (proteção social), estabilidade, tendo o Estado como regulador e mediador entre trabalho e capital (proletários e empregadores).

A passagem para o sistema toyotista, ocorrida em decorrência do processo de globalização e da imposição do neoliberalismo em face do enfraquecimento do socialismo na maioria dos países, rompeu fortemente com o sistema de proteção social, justificando pela necessidade de enxugamento dos gastos públicos, sob o ideário do Estado Mínimo, que teve como principais defensores Ronald Reagan, nos EUA, e Margareth Thatcher, na Inglaterra, principais potências econômicas do mundo àquela época. Tal período, representado historicamente entre 1950-1980 não teve, aqui no Brasil, as mesmas características desses países centrais do capitalismo, haja vista que nosso processo de desenvolvimento nacional se processou de modo periférico e dependente.

A partir da década de 1980 rompe-se com a concepção de trabalho como emprego formal, como contrato por tempo integral e com perspectiva de estabilidade. Mundialmente, a flexibilização passa a ser o farol a iluminar as novas relações trabalhistas. $\mathrm{O}$ trabalho passa a carecer de rumo pré-determinável, assumindo sentido caótico, materializado (ou desmaterializado) pela desregulação das relações trabalhistas, redução do poder sindical, retirada de direitos, cortes de salários. Esta desestruturação do mercado de trabalho gerou altas taxas de desemprego, redundando em aumento da informalidade, de subemprego, de trabalho precário, subcontratado, em tempo parcial, entre outros disfarces do desemprego estrutural (POCHMANN, 2012).

Dentre outros efeitos colaterais da racionalidade neoliberalista que o modo capitalista de produção vem impondo a fim de satisfazer os interesses de uma minoria - classe burguesa - a passagem do sentimento coletivo (o sindicalismo como exemplo) para o individualismo, através do ideário da competitividade, da meritocracia, do capital humano, os quais visam que o trabalhador internalize a responsabilidade por sua "incompetência e fracasso" para obter um emprego é única e exclusivamente sua.

4 Welfare State ou "Estado de Bem Estar Social", segundo Gomes (2006), pode ser compreendido como um conjunto de serviços e benefícios sociais de alcance universal promovidos pelo Estado com a finalidade de garantir uma certa "harmonia" entre o avanço das forças de mercado e uma relativa estabilidade social, garantindo aos indivíduos um mínimo de base material a fim de que possam enfrentar os efeitos deletérios de uma produção capitalista desenvolvida e excludente (GOMES, 2006, p. 203). 
Aqui percebemos uma contradição histórica e permanente no Brasil: uma sociedade do trabalho, sem trabalho (ALVES; ANTUNES, 2004). Segundo a teoria clássica marxiana, a categoria de divisão social do trabalho é a base mais importante de toda organização social e a origem da divisão de classes, gênese da exclusão e desigualdades perpetradas pelo modo capitalista de produção. O papel ontológico e central do trabalho defendido por Marx (2011) em sua especificidade histórica, tendo como referencial o proletário da Revolução Industrial pode muito bem continuar servindo-nos de ponto fulcral para análise social tendo desta vez como referencial o "colaborador" moderno.

Este profundo processo de mudanças que vem se processando no sistema capitalista, desde a década de 1980, sintetizado em três eixos principais: neoliberalismo, reestruturação produtiva e globalização do capital, foi denominado por Harvey (1993) de "acumulação flexível".

O trabalho, em razão destas mutações, vem a ser, portanto, uma categoria analítica-chave para o entendimento das sociedades dos nossos tempos. Desta forma,

\begin{abstract}
para os trabalhadores, é a produção simbólica sobre as relações sociais no trabalho que confere sentido e orienta suas percepções, atitudes, pertenças e comportamentos (individuais e coletivos). Por isso mesmo, o âmbito do trabalho é o lócus da produção social de bens e serviços e, simultaneamente, o lócus da produção de ideias, de representações e simbolizações. [...] Tal produção simbólica está, ela mesma, enraizada na vida social que ocorre dentro e fora dos espaços onde se tecem as relações sociais de trabalho. (GUIMARÃES, 2005 p. 152).
\end{abstract}

Para os jovens da modernidade, conforme Weller (2014), o trabalho aparece como categoria central entre as opiniões, expectativas, atitudes e relatos de uma amostra de 3.501 estudantes de Ensino Médio, com idade entre 15 e 24 anos, distribuídos entre as cinco regiões geográficas do Brasil (ABRAMO; BRANCO, 2005). Neste levantamento o trabalho é apontado como o quesito que mais preocupa os jovens, e o desemprego é o problema mais importante para $30 \%$ das respostas. Ou seja, é por sua ausência, falta, desemprego ou não-trabalho que o trabalho se destaca na agenda juvenil, não importando se o respondente tem ou não emprego, se procura ou não trabalho.

Nesta perspectiva, a escola de Ensino Médio coincide com um período da vida dos jovens em que se espera que estes planejem seus projetos de futuro, de vida, realizando as transições necessárias, a fim de viabilizá-los.

Assim como o sentido do Ensino Médio pode ser pensado apenas como uma fase transitória e de preparação visando quase somente um futuro pós conclusão e obtenção do diploma, a juventude também acaba sendo idiossincraticamente rotulada como um período provisório e passageiro, entre a infância e a idade adulta.

Desta forma, o ser social jovem é omitido quando a escola e seus processos educativos só o percebem (reduzindo-o) sob a condição de aluno, ser aprendente e passivo. Tal premissa se estabelece mediante o processo de ensino-aprendizagem através de conteúdos curriculares fragmentados, com ênfase nos projetos profissionais dos estudantes, em detrimento dos projetos de vida dos jovens-estudantes.

Esta lógica que vem hegemonizando e homogeneizando as práticas e saberes escolares do ensino médio desde a instituição da Lei de Diretrizes e Bases (LDB - Lei no 9394/96) (BRASIL, 1996), apesar da previsão legal em contrário, desconsidera que os tempos e espaços juvenis de aprendizagem, de formação, experimentação e vivência juvenil são experienciados de modos desiguais pelos jovens, em razão de diversos determinantes como condição social, sexo masculino, feminino, negros, do meio rural, urbano, periferia, entre outros.

A escola se constitui em importante instituição de socialização para a elaboração dos projetos de vida juvenis, mas ao permanecer restrita à formação e preparação ao mercado de trabalho, numa visão reducionista e instrumental, acaba por reproduzir as condições materiais para a manutenção 
das exclusões e precariedade, pois não se permite modificar a si mesma (ou modifica-se em velocidade mais lenta que as demandas juvenis exigem) a fim de atender a estas demandas de forte conteúdo e significado simbólico para a construção de suas biografias e identidades, com sentido e propósito, a partir de suportes educacionais.

Assim, não existe fórmula mágica: cada instituição escolar deve desenvolver atividades aula e extra aula, vivências e debates nos espaços escolares, seminários, oficinas, relações de confiança e canais de diálogo aberto com os jovens, ações que enfim, possibilitem a elaboração e construção de seus projetos de vida.

As propostas político-pedagógicas da Rede Federal de Educação, Ciência e Tecnologia vem ao encontro desses anseios juvenis, ao buscar compromisso político e ideológico em romper com a dualidade histórica da educação brasileira: educação profissionalizante para as massas populares e educação propedêutica e super especializada para as elites burguesas.

Através da Educação Profissional e Tecnológica, garantida através da Lei no 11.892/2008 (BRASIL, 2008), os Institutos Federais, pulverizados nas mais longínquas localidades rurais e urbanas do Brasil (visando ao desenvolvimento regional) vem lutando por um modelo de educação para os jovens baseado no trabalho como princípio educativo e na indissociabilidade entre educação e trabalho, visando uma formação humana, integral, omnilateral, tendo na ciência, cultura, tecnologia e no trabalho suas bases conceituais e ênfase principal. Esta nova proposta também é política ao buscar um projeto social contra hegemônico e de confronto aos estritos interesses do capital (FRIGOTTO, 2007), concebendo os sujeitos juvenis como mercadoria ${ }^{5}$ (BAUMAN, 2008).

Retomando as explicações iniciais sobre transformações econômicas, produtivas e trabalhistas em razão da transição do modo fordista/taylorista para o modo toyotista de produção, Harvey (1993) estabelece nova categoria analítica-chave a nos auxiliar a compreensão (ainda que parcial) social da modernidade: a "compressão espaço-tempo". Tal concepção nos permite perceber como nossos tempos e espaços estão condicionados (subsumidos) à metanarrativa/racionalidade econômico-mercadológica e financeira do capital global.

Harvey (1993) nos explica que, assim como o capital necessita estar em permanente processo de mudança a fim de garantir sua preservação, as práticas e processos sociais que o materializam também se modificam, buscando acompanhar a velocidade dessas mudanças. Assim, o tempo de giro do capital (intersecção entre dinheiro, espaço e tempo) seria uma das categorias centrais para o entendimento da aceleração dos ritmos e intensidades do trabalho, dos processos produtivos e das relações sociais como um todo. Tais acelerações de tempos visam gerar mais lucros (mais-valia) no menor tempo possível, que se torna requisito fundamental de sobrevivência dos empreendimentos empresariais nos ultracompetitivos mercados de capitais globalizado.

Como exemplos de aceleração dos tempos de giro temos: as inovações tecnológicas e organizacionais, as linhas de montagem, a obsolescência planejada de produtos, o sistema just in time e kanban de produção etc. Os exemplos de compressão dos espaços são: a rede mundial de computadores (internet), o sistema internacional financeiro de bancos, a bolsa mundial de valores, entre outros, que funcionam comprimindo os espaços geográficos e encurtando as relações sociais, que tornam mais rápidas, ágeis e instantâneas.

Estas novas configurações impostas ao mundo do trabalho exigem um trabalhador multifuncional e polivalente, flexível, disponível a qualquer momento e submisso (dócil segundo a teoria foucaultiana) a realizar as mais diversas atividades laborais na empresa em que trabalha, em razão do alto risco de ser demitido sem grandes problemas com a justiça trabalhista (que desmonta os

5 Tal conceito emerge do "fetichismo da mercadoria" criado por Karl Marx (2011) como censura à falácia utilizada pela ideologia capitalista de esconder a dimensão subjetiva e humana das relações, tendo na mercadoria o centro de interesses e não na dimensão humana que se torna cada vez mais desumana quando ocultada sob a lógica da circulação de mercadorias, através da compra e venda da capacidade de trabalho, afastada de todo seu conteúdo emocional, psicológico, social, cultural, etc., de que o ser humano necessita para humanizar-se. 
direitos conquistados historicamente pelos trabalhadores progressivamente), e ante o aumento progressivo do desemprego e da qualificação destes desempregados, estratégia destes últimos para se reinserirem ao mercado de trabalho.

Nesta seara, o Brasil, por ter se inserido na economia global de forma dependente e subalterna, ausência de uma política industrial ativa, comercial defensiva e social compensatória, acabou produzindo um exército de desempregados, transformando-se em uma grande feira de concorrência mundial pelos menores custos possíveis de mão-de-obra, disputada por grandes corporações transnacionais, compradoras de força de trabalho. Este tipo de "exploração legalizada" acaba por fazer desacreditar na propaganda idealizada no imaginário coletivo de que a globalização e o capitalismo produziriam um mundo mais homogêneo, com melhor repartição da riqueza, produção, trabalho e poder (POCHMANN, 2012).

A forte crise econômica que abala o mercado atualmente é percebida pelos jovens em seu cotidiano, através dos exemplos refletidos por seus pais, amigos, vizinhos, familiares, o que lhes causa angústia e temor diante de um cenário de futuro incerto e, por isso, assustador.

Apesar de termos de reconhecer que a política pública de criação de vagas de emprego para amenizar a premência de estratégias de sobrevivência para milhares de jovens brasileiros, não podemos desconsiderar que a criação automática de ocupações, desintegradas das circunstâncias regionais e locais de cada contexto socioeconômico, seria apenas uma medida paliativa e não estrutural, já que a maioria dos postos que estes jovens ocupam possuem graves precariedades, conforme estudo Trabalho Decente e Juventude, da Organização Internacional do Trabalho (SILVA, 2015), em que direitos básicos de dignidade, conciliação entre trabalho e estudo, salário mínimo, etc., não são respeitados.

Outra perspectiva que se levanta no campo da sociologia da juventude, seria a moratória social ${ }^{6}$. Entretanto, este tempo de preparação, formação, vivência e aproveitamento das coisas boas do "ser jovem", de forma a retardar ao máximo o tempo deste contingente entrar ao mercado de trabalho, adquirindo mais qualificação e aperfeiçoamento contrasta fortemente com a necessidade imperiosa que muitos destes jovens têm de obter renda, seja para enfrentamento da pobreza, para ajudar sua família, para sua autonomia ou mesmo realização pessoal, pois através do poder de compra, conseguem garantir mobilidade urbana, produtos materiais e simbólicos, garantia de direitos essenciais, como alimentação, moradia, educação, saúde, etc.

\section{Considerações finais}

Para além do conhecimento técnico-profissionalizante, os alunos que cursam a EPT parecem buscar experimentação para responder a muitas de suas dúvidas sobre o mercado de trabalho, como um "termômetro" ou "mapa de orientação" a fim de que possam ter as mínimas condições de acesso a informações e relações que lhes subsidiem (ainda que precariamente) a tomarem decisões profissionais e de estudos relevantes a seus projetos de vida.

A dramática realidade que se estabelece no Brasil atualmente é que as taxas de crescimento econômico são insuficientes para a demanda de criação de empregos, não conseguindo absorver sequer os novos ingressantes da População Economicamente Ativa, o faz expandir em proporções preocupantes o contingente total de desempregados.

\footnotetext{
6 Segundo Groppo (2017), o termo “moratória social” refere-se a um conceito amplo, criado pelo sociólogo alemão Karl Mannheim, o qual considera a juventude como força social capaz de mobilizar-se em favor da democracia. Defende a ideia de que a juventude é um tempo especial do curso da vida para a experimentação, um tempo-espaço que deveriam ser direitos inalienáveis a todos cidadãos políticos, visando sua formação crítica, humana, cultural, recreativa, seu lazer, em confronto à mera segregação por faixas etárias e à disciplinarização imposta pelas gerações adultas e pelo sistema neoliberalista/capitalista, que tende a condicionar e manipular as vidas das pessoas através das racionalidades reducionistas, mercadológicas e economicistas.
} 
Cabe também destacar que apesar da existência de oportunidades de ocupação para mão-de-obra juvenil, os trabalhadores adultos desempregados acabam preenchendo essas vagas em razão de suas "vantagens comparativas" (maior experiência comprovada em carteira de trabalho, maior capacitação profissional especializada), enquanto muitos jovens possuem experiência mas não podem comprovar: falta-lhes as transcrições omitidas em suas carteiras de trabalho em razão do período que trabalharam desprotegidos socialmente e previdenciariamente, sem carteira assinada.

Além da premência das políticas públicas voltadas à imediata inserção dos jovens em atividades econômicas produtivas, há forte necessidade de aprofundar-se análises sobre as demandas, aspirações e expectativas da população juvenil ante trabalho e renda.

Analisar os sentidos e dimensões do trabalho para estes jovens implica em não o reduzir à inserção destes ao "mundo dos empregos", mas também buscar compreender como este mundo do trabalho é atravessado por relações sociais de gênero, raça, etnia, idade, classe social, o que produz novos significados para além da simples obtenção de uma renda. Nesta perspectiva, o trabalho adquire múltiplos sentidos (CORROCHANO, 2014).

Duas características importantes marcam a relação entre escola e trabalho no Brasil: o ingresso precoce no trabalho e a premência em conciliar trabalho e estudo. Por este motivo, há necessidade de expansão da reflexão acerca do papel da escola de Ensino Médio, sob as bases conceituais da EPT, a fim de que os jovens construam de forma mais consciente e elaborada seus projetos de vida.

Através dos discursos juvenis analisados por percebe-se que nem os profissionais de educação nem suas famílias compreendem adequadamente as dificuldades destes jovens em descobrir seus talentos, habilidades, anseios e medos em relação à profissão a escolher. Como não conseguem obter experimentação que lhes possibilite transformar seus "sonhos em realidade", muitos jovens são estereotipados pelos adultos como "sonhadores", "confusos", "indecisos", o que deprecia ainda mais sua autoestima e motivação pessoal, em conjunto com as já citadas ideologias neoliberalistas que atribuem exclusivamente ao desempregado a responsabilidade por sua condição (CARRANO; DAYRELL, 2014).

As análises aqui desenvolvidas demandam um olhar mais crítico e reflexivo por parte dos Institutos Federais e especialmente investigações mais específicas em cada contingente juvenil singular, em decorrência das grandes desigualdades de desenvolvimento econômico, político e social entre as regiões do Brasil, e a realidade concreta dos jovens.

Relevante, portanto, reconhecer que a empreitada aqui realizada se limita a um estudo geral e panorâmico da juventude brasileira sob o prisma de categoria histórico-social, dotada de direitos, voz e protagonismo, na luta pela construção de uma sociedade mais justa, equânime e com menos desigualdades.

Permanece, portanto, necessidade de aprofundamento investigativo sobre as possíveis alternativas educativas do Ensino Médio através da EPT que possam acabar com os retumbantes silêncios e invisibilidades como que as escolas de nível médio vêm tratando o tema das implicações entre o mundo do trabalho e o projeto de vida para seus jovens, que são a alma e a razão de ser de cada instituição de ensino deste nível.

A escola, como espaço-tempo de viver e desenvolver a condição juvenil pode constituir-se como suporte a estes jovens alunos, não os deixando como náufragos à deriva ou solitários viajantes rumo a terras desconhecidas, durante e após a formação do Ensino Médio. Inicialmente, devemos reconhecer a relevância desta temática e, após, conhecer, conversar, debater, dialogar, analisar e compreender mais e melhor os sentidos que estes jovens atribuem ao trabalho e a seus projetos de vida. Tais práticas podem representar o aprimoramento das escolas como instituição de construção democrática, de cidadania e desenvolvimento integral do ser humano, desconstruindo a visão minimalista de idealizá-la com sentido exclusivamente intelectual-cognitivo e de adestramento pragmático ao mercado de trabalho. 


\section{Referências}

ABRAMO, Helena Wendel; BRANCO, Pedro Paulo Martoni. (org.). Retratos da Juventude Brasileira: análises de uma pesquisa nacional. 1. ed. São Paulo: Fundação Perseu Abramo, 2005.

ALVES, Giovanni; ANTUNES, Ricardo. As mutações no mundo do trabalho na era da mundialização do capital. Educação \& Sociedade, Campinas, v. 25, n. 87, p. 335-351, maio/ago. 2004. Disponível em: https://www.scielo.br/pdf/ es/v25n87/21460.pdf. Acesso em: 10 ago. 2020.

ANTUNES, Ricardo. Os sentidos do trabalho: ensaio sobre a afirmação e a negação do trabalho. 11. ed. São Paulo: Boitempo, 2009.

BAUMAN, Zigmunt. Tempos líquidos. Rio de Janeiro: Zahar, 2007.

BAUMAN, Zigmunt. Vida para consumo. Rio de Janeiro: Zahar, 2008.

BRASIL. Lei no 11.892, de 29 de dezembro de 2008. Institui a Rede Federal de Educação Profissional, Científica e Tecnológica, cria os Institutos Federais de Educação, Ciência e Tecnologia, e dá outras providências. Brasília, DF: Presidência da República, [2008]. Disponível em: http://www.planalto.gov.br/ccivil_03/_ato2007-2010/2008/lei/111892. htm. Acesso em: 20 abr. 2020.

BRASIL. Lei no 9.394, de 20 de dezembro de 1996. Estabelece as diretrizes e bases da educação nacional. Brasília, DF: Presidência da República, [1996].

CARRANO, Paulo; DAYRELL, Juarez Tarcísio. Juventude e Ensino Médio: quem é este aluno que chega à escola? In: CARRANO, Paulo; DAYRELL, Juarez; MAIA, Carla Linhares (org.). Juventude e Ensino Médio: sujeitos e currículo em diálogo. Belo Horizonte: Editora UFMG, 2014. p. 101-134.

CORROCHANO, Maria Carla. Jovens no Ensino Médio: qual o lugar do trabalho? In: CARRANO, Paulo; DAYRELL, Juarez; MAIA, Carla Linhares (org.). Juventude e Ensino Médio: sujeitos e currículo em diálogo. Belo Horizonte: Editora UFMG, 2014. p. 205-228.

DAYRELL, Juarez Tarcísio; LEÃO, Geraldo; REIS, Juliana Batista dos. Juventude, projetos de vida e ensino médio. Educação \& Sociedade, Campinas, v. 32, n. 117, p. 1067-1084, out./dez. 2011. Disponível em: https://www.scielo.br/pdf/ es/v32n117/v32n117a10.pdf. Acesso em: 17 abr. 2020.

ENGELS, Friedrich; MARX, Karl. A Ideologia Alemã. Tradução: Luciano Cavino Martorano, Nélio Schneider e Rubens Enderle. 1. ed. São Paulo: Boitempo, 2007.

FRIGOTTO, Gaudêncio. Educação e a crise do capitalismo real. 6. ed. São Paulo: Cortez, 2010.

FRIGOTTO, Gaudêncio. A polissemia da categoria trabalho e a batalha das ideias nas sociedades de classes. Revista Brasileira de Educação, Campinas, v. 14, n. 40, p. 168-194, jan./abr. 2009. Disponível em: https://www.scielo.br/pdf/ rbedu/v14n40/v14n40a14.pdf. Acesso em: 5 abr. 2020.

FRIGOTTO, Gaudêncio. A relação da educação profissional e tecnológica com a universalização da educação básica. Educação \& Sociedade, Campinas, v. 28, n. 100, p. 1129-1152, out. 2007. Disponível em: https://www.scielo.br/pdf/es/ v28n100/a2328100.pdf. Acesso em: 20 jun. 2020.

GENTILLI, Pablo. O que há de novo nas novas formas de exclusão na educação? Neoliberalismo, Trabalho e Educação. Educação e Realidade, Porto Alegre, v. 20, n. 1, p. 191-202, jan./jun. 1995. Disponível em: https://seer.ufrgs.br/educacaoerealidade/article/view/71754/40691. Acesso em: 10 abr. 2020.

GOMES, Fábio Guedes. Conflito social e welfare state: Estado e desenvolvimento social no Brasil. RAP - Revista de Administração Pública, Rio de Janeiro, v. 40, n. 2, p. 201-236, mar./abr. 2006. Disponível em: https://www.scielo.br/ pdf/rap/v40n2/v40n2a03.pdf. Acesso em: 15 jul. 2020.

GROPPO, Luís Antonio. Introdução à sociologia da juventude. Jundiaí: Paco Editorial, 2017.

GUIMARÃES, Nadya Araujo. Trabalho: uma categoria-chave no imaginário juvenil? In: ABRAMO, Helena Wendel; BRANCO, Pedro Paulo Martoni (org.). Retratos da Juventude Brasileira: análises de uma pesquisa nacional. 1. ed. São Paulo: Editora Fundação Perseu Abramo, 2005. p. 149-174.

HARVEY, David. Condição pós-moderna: uma pesquisa sobre as origens da mudança cultural. Tradução: Adail Ubirajara e Maria Stela Gonçalves. 3. ed. São Paulo: Edições Loyola, 1993.

INSTITUTO BRASILEIRO DE GEOGRAFIA E ESTATÍsTICA (IBGE). Pesquisa Nacional por Amostra de Domicílios Contínua. Indicadores IBGE, Rio de Janeiro, ano 37, jul./set. 2019. Disponível em: https://static.poder360.com. br/2019/11/pnad-trimestral-3tri19.pdf. Acesso em: 25 ago. 2020. 
LUKÁCS, George. Ontologia do ser social II. 1. ed. São Paulo: Boitempo, 2013.

MANACORDA, Mario Alighiero. Marx e a pedagogia moderna. Tradução: Newton Ramos de Oliveira. Campinas: Alínea, 2007.

MARX, Karl. O Capital: crítica da economia poítica. Tradução: Rubens Enderle. 2. ed. São Paulo: Boitempo, 2011.

POCHMANN, Márcio. O emprego na globalização, a nova divisão internacional do trabalho e os que o Brasil escolheu. São Paulo: Boitempo, 2012.

SAVIANI, Dermeval. Trabalho e Educação: fundamentos ontológicos e históricos. Revista Brasileira de Educação, Campinas, v. 12. n. 34. p. 152-180, jan./abr. 2007. Disponível em: https://www.scielo.br/pdf/rbedu/v12n34/a12v1234. pdf. Acesso em: 3 ago. 2020.

SCHÜTZ, Alfred. Fenomenologia e relações sociais. 2. ed. São Paulo: Zahar, 1979.

SILVA, Enid Rocha Andrade da (coord.). Juventude e trabalho informal no Brasil. In: ORGANIZAÇÃO INTERNACIONAL DO TRABALHO. Trabalho decente e juventude. Brasília, DF: Editora IPEA: Editora Organização Internacional do Trabalho, 2015. p. 11-66. Disponível em: https://www.ilo.org/wcmsp5/groups/public/---americas/---ro-lima/---ilo-brasilia/documents/publication/wcms_526213.pdf. Acesso em: 10 jun. 2020.

SILVA, Enid Rocha Andrade da et al. A informalidade do trabalho da juventude no Brasil: o que pensam os/as integrantes do subcomitê da agenda nacional de trabalho decente para a juventude. In: ORGANIZAÇÃO INTERNACIONAL DO TRABALHO. Trabalho decente e juventude. Brasília, DF: Editora IPEA: Editora Organização Mundial do Trabalho, 2015. p. 8-54. Disponível em: http://repositorio.ipea.gov.br/bitstream/11058/5857/1/A\%20informalidade $\% 20$ do $\% 20$ trabalho\%20da\%20juventude\%20no\%20Brasil_o\%20que\%20pensam\%20os_as\%20integrantes\%20do\%20Subcomit\%C3\%AA\%20da\%20Ag\%C3\%AAncia\%20Nacional\%20de\%20Trabalho\%20Decente\%20para\%20a\%20Juventude. pdf. Acesso em: 10 jun. 2020.

WELLER, Wivian. Jovens no Ensino Médio: projetos de vida e perspectivas de futuro. In: CARRANO, Paulo; DAYRELL, Juarez; MAIA, Carla Linhares (org.). Juventude e Ensino Médio: sujeitos e currículo em diálogo. Belo Horizonte: Editora UFMG, 2014. p. 135-154.

Data de submissão: 02/01/2021

Data de aceite: 29/01/2021 
